\title{
The Effect of Environmental Criteria on Locating a Biorefinery: a Green Facility Location Problem
}

\author{
Adrian Serrano-Hernandez*, Javier Faulin*, \\ Javier Belloso*, Bartosz Sawik**
}

\begin{abstract}
Underestimating facility location decisions may penalize business performance over the time. These penalties have usually been studied from the economic point of view, analyzing its impact on profitability. Additionally, the concern about obtaining sustainability is gaining importance, leading to a search for renewable energy sources to reduce greenhouse gas emissions. However, little attention has been paid to choosing a location considering environmental criteria. Thus, this work aims at determining a biorefinery location considering its impacts on natural resources. Therefore, a mixed integer linear programming (MILP) model has been developed, taking into account crop location and biomass production seasonality to obtain a proper location that minimizes environmental impact.

The initial version of this paper was presented at the ICIL Conference in 2016.
\end{abstract}

Keywords: biorefinery, logistics, supply chain management, facility location problem, MILP Mathematics Subject Classification: 90B80 90C11

Submitted: January 25, 2017

Revised: June 1, 2017

\section{INTRODUCTION}

Biorefineries have rapidly evolved in order to reduce our dependence on oil materials and their derivatives. This dependence may be solved by developing new energy alternatives from renewable resources. To this respect, biomass is seen as an important option to replace the use of fossil fuels, especially in the transportation sector. This substitution can be done because biorefineries transform biomass into liquid fuel for internal combustion engines (Börjesson et al., 2014) and electricity for electric vehicles (Juan et al., 2016). Thus, biofuels are considered a promising alternative to conventional fossil fuel in the short and medium terms. The European Union is heavily dependent on imported energy resources, especially oil. Actually, $65 \%$ of oil

\footnotetext{
* Public University of Navarre, Department of Statistics and Operations Research, Institute of Smart Cities, Spain, e-mail: adrian.serrano@unavarra.es

** AGH University of Science and Technology, Faculty of Management, Krakow, Poland
} 
consumption in the EU is used in the transport sector, which contributes to increased greenhouse gas emissions (European Environment Agency, 2015). Most biorefineries have focused their interests and goals on bioethanol or biodiesel production, helping contribute to such an energy goal (Papendiek et al., 2016). However, biofuels are produced in large quantities but are sold at low prices, making its profitability strongly dependent on market conditions. This is very difficult to control (oil and biomass prices), so it results in a high-volatility business. The biorefinery concept has evolved into new scenarios where biofuel production is complemented with other high-value chemical commodities in order to remedy that situation. Once it has been collected, biomass is converted into energy (for instance, electricity and heat) as well as chemical commodities through the biological and/or thermochemical processes that take place in the facility called the biorefinery (Cherubini et al., 2009).

Biorefinery location is a critical factor, since many tactical and operational decisions (e.g., crop selection, purchase policies, or stock policies) will depend on it (Daskin, 2013). The process of locating an industrial plant requires an analysis of several factors from many points of views: economic, social, technological, market, environmental, etc. Facility location decisions have a strategic nature. Generally, they have long-lasting consequences that involve the whole company. Then, operational and tactical decisions are made based on the strategical infrastructure. For this reason, the scientific literature has tried to provide answers for the many questions related to the best place to locate a facility. The answers lie in the resolution of the Facility Location Problem (FLP).

Finally, this work makes a contribution in the scarce field biorefinery location, solving a real optimization problem within a rather-new FLP variant: the Green FLP. The remainder of this paper is structured as follows: Section 2 introduces related literature. The problem definition is presented in Section 3, and the results of the computational experiments are presented and discussed in Section 4. Managerial insights are given in Section 5.

\section{RELATED LITERATURE}

Several FLP variants arise from the literature. For instance, Montoya et al. (2016) dealt with a multi-product FLP running a computational experiment over 288 instances with an average optimality gap of around $3 \%$. A stochasticity approximation to location problems are described by Serrano-Hernandez et al. (2015) and Bieniek (2015), where the randomness concept surges on production and demand difficulties in biorefinery analysis, respectively. Ortiz-Astorquiza et al. (2015) did a theoretical study on the multi-level FLP, which mainly consists of finding the best set of facilities to open for each level in order to maximize the total profit, satisfying the demand of every customer. Another FLP variant is the Location Routing Problem in which an FLP and a Vehicle Routing Problem are considered at the same time (Koç et al., 2016). A rich collection of multi-objective FLP literature can be explored, such as Bashiri and Rezanezhad (2015) and Gutjahr and Dzubur (2016). In this sense, the works from Liu et al. (2014) are particularly interesting; Harris et al. (2014) and Zhao and Verter (2015) took into account environmental-related objective functions. Finally, the 
recent word developed by Martinez and Fransoo (2017) reviewed the specific literature about Green Facility Location, concluding the necessity of further research in that field in two directions: (i) incorporating new models to estimate a wider range of environmental impacts, and (ii) assessing the energy efficiency of the facility itself.

FLP applications are unlimited, and there are some typical examples of them. Such is the case of health care problems, in which health care centers (typically hospitals, as pointed out by Chatterjee and Mukherjee, 2013) should be located in order to maximize the assistance or coverage level. For instance, Beliën et al. (2013) optimally placed some organ transplant centers. Few papers have considered biorefinery location from an analytical viewpoint. Most of them are supported by Geographical Information Systems such as Yu et al. (2014), using Net Present Value as function objective to be maximized (Marvin et al., 2012) as well as multiobjective programming where You et al. (2012), for instance, considered economic and environmental criteria. Finally, a remarkable work is described in the Memişoğlu et al. (2015) paper in which a bioenergy supply chain is designed. They explicitly consider location, production, inventory, and distribution problems to design the conjoint decisions of a biorefinery supply.

Exact solutions through Mixed Integer Linear Programming problems can be easily found in the literature, as depicted by Melo et al. (2009). According to the authors, exact solution procedures represent more than a half of their reviewed literature. Heuristics algorithms have been developed for the FLP and many of its variants as well. That is the case of Lee and Lee (2010), with a tabu search heuristic to solve a generalized hierarchical covering FLP. Similarly, Aytug and Saydam (2002) and Shavandi and Mahlooji (2006) solved the same problem with a genetic algorithm. Other examples are as follows: Berman et al. (2007), who developed a greedy algorithm for a generalized maximal covering location problem; and Sakakibara et al. (2012), who simultaneously solve the storage and delivery problem using a relax-and-fix heuristic.

\section{PROBLEM DEFINITION}

In the same way that green logistics extends the traditional definition of logistic by explicitly taking into account other non-traditional external costs within all aspects of logistics, a Green FLP cares about environmental issues such as air pollution. Air pollution is caused by the emission of air pollutants like particulate matter (PM), $\mathrm{NO}_{\mathrm{x}}$, and non-methane volatile organic compounds that affect people, vegetation, materials, and the global climate. Climate change or global warming impacts of road transport are mainly generated by emissions of greenhouse gases (GHG): carbon dioxide $\left(\mathrm{CO}_{2}\right)$, nitrous oxide $\left(\mathrm{N}_{2} \mathrm{O}\right)$, and methane $\left(\mathrm{CH}_{4}\right)$. Nevertheless, $\mathrm{CO}_{2}$ is the dominant anthropogenic GHG, and the remaining GHG can be expressed as $\mathrm{CO}_{2}$ equivalent $\left(\mathrm{CO}_{2 \mathrm{e}}\right)$ (Lera-López et al., 2014).

As previously mentioned, the facility location problem is a strategic decision that will affect tactical and operational decisions when the facility is already running. For example, economically speaking, a facility should be placed in a city center, raising congestion in the area with noisy and pollutant delivery trucks. People who will suffer from such nuisances due to the pure economic decision would pay for those external costs. For this reason, a Green FLP should take into account the whole environmental 
performance due to the location decision. That is, the sustainability facility itself is outside the scope of this article since it is not related to location decisions.

Air pollution occurs when fuel is burnt; therefore, everything that affects fuel consumption will affect emissions as well. Distance is the major determinant of fuel consumption; however, there are many other factors that can be divided into four groups (Demir et al., 2014): (i) vehicle-related, which includes the curb weight or type of fuel it uses; (ii) environment-related, such as the road gradient, pavement type, and even temperature and altitude; (iii) travel-related, that would include speed and acceleration or deceleration; and finally (iv) driver-related, such as driver aggressiveness and gear selection. From these factors, speed and load are the most-important ones, being the reason why applying an average emission value per kilometer is not accurate. Later, road gradient plays an important role in fuel consumption, keeping in mind that downhill travel does not compensate for uphill travel. The remaining factors still marginally affect energy consumption.

The problem addressed in this article is stated as follows. In a $10,000 \mathrm{~km}^{2}$ study area embracing the whole Autonomous Community of Navarre in Spain, we are given a set of crops that currently produce winter cereal (oats, barley, wheat, and corn), rapeseed, rice, and alfalfa (those are the products where the biomass comes from); all of which are suitable for a lignocellulosic biorefinery. Table 1 summarizes the main characteristics regarding the harvest times, humidity rates, and market prices of the aforementioned biomasses (Department of Agriculture of Navarre, 2016).

Table 1. Biomass summary

\begin{tabular}{|c|c|c|c|}
\hline Biomass & Harvest times & Humidity (\%) & Price (€/ton) \\
\hline Winter Cereal & June - August & 10 & $50-60$ \\
\hline Corn & November - January & 23 & $45-65$ \\
\hline Alfalfa & March - October & 58 & $75-105$ \\
\hline Rapeseed & July - August & 10 & $65-85$ \\
\hline Rice & October - November & 25 & $50-70$ \\
\hline
\end{tabular}

The geographical scope is represented in Figure 1, with the green dots representing the location of the crops and the pink triangles the potential locations for hosting a biorefinery (industrial parks). Since all of the current biomass production cannot be collected for a biorefinery (Luo et al., 2010), for each product and crop, an availability factor $(\alpha)$ is given in order to guarantee sustainability (soil, prices, animal feeding, etc.). This means the proportion of the total resources availability that could effectively be used for supplying a biorefinery. These exploitation factors were carefully chosen conjointly with the Navarrese Agricultural Department based on soil characteristics and current agricultural practice. Additionally, the biorefinery will sign long-term supply contracts with providers in order to guarantee a continuous flow of biomass. Storage is allowed in origin and destination; that is, once collected, the biomass can wait in either the production location or biorefinery warehouse with a known time-dependent depreciation rate. With regard to the location candidates, we use all of the industrial 
parks in the study area that are able to host such a facility. Biorefinery capacity is determined from the supply side, accounting for 150,000 tons of dried biomass during the whole year; i.e., a biorefinery processes 12,500 tons of biomass monthly. Finally, having the purpose of making comparisons, genuine data about biomass prices (of each product), transportation costs, and storage costs are known.

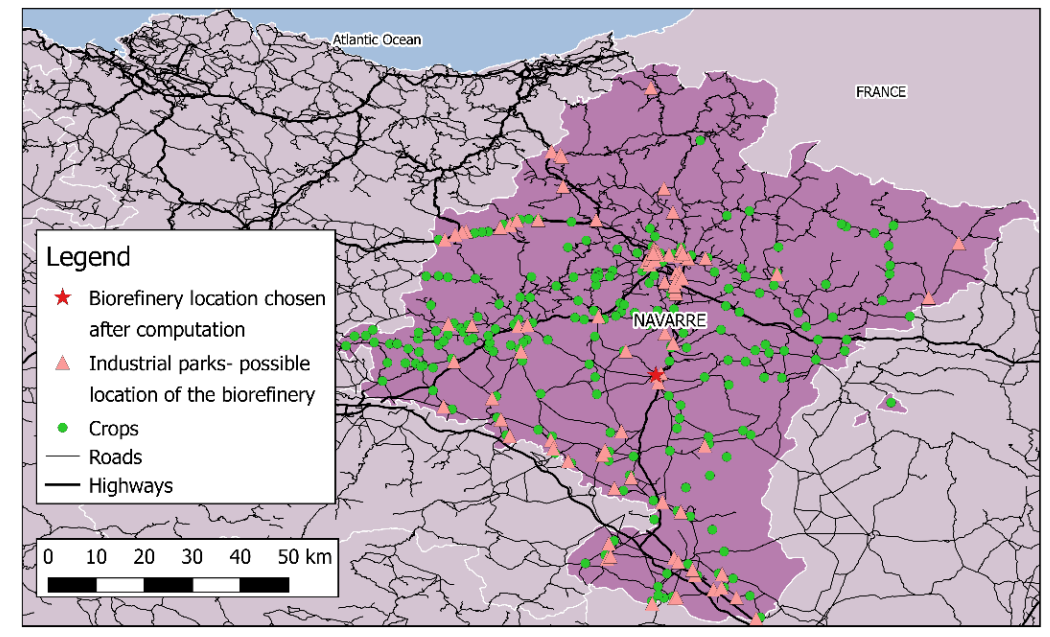

Fig. 1. Geographical scope of the problem

A Mixed Integer Linear Programming (MILP) model is developed to determine the best location to place the abovementioned biorefinery and to determine the tactical and operational decisions (e.g., crop selection, purchase policies, or stock policies) minimizing the environmental impact. Here, the environmental impact can be measured as the distance between the crops and the chosen biorefinery location. Due to the supply chain configuration, routing is impossible, since vehicles leave the biorefinery empty and return full once a crop is collected. For the same reason, payload consideration in the model can be dropped out. Vehicle-related factors are not taken into account because their capacities are not considered in this model: there is only one type of truck with unlimited units. Finally, the study area has no significant road gradient differences.

The sets are defined in Table 2, whereas the variable decisions are depicted in Table 3 and parameters in Table 4.

Table 2. Description of sets

\begin{tabular}{|c|l|l|}
\hline Set & \multicolumn{1}{|c|}{ Description } & \multicolumn{1}{|c|}{ Range } \\
\hline$I$ & Set of crops & $i=1,2 \ldots 221$ \\
\hline$J$ & Set of potential biorefineries & $j=1,2 \ldots 100$ \\
\hline$P$ & Set of products & $p=$ oat, barley $\ldots$ alfalfa \\
\hline$T$ & Set of months & $t=1,2 \ldots 12$ \\
\hline
\end{tabular}


Table 3. Description of variables

\begin{tabular}{|c|l|}
\hline Variable & \multicolumn{1}{|c|}{ Description } \\
\hline$X_{j}$ & 1 if the biorefinery is built in potential location $j ;, 0$ otherwise \\
\hline$Y_{j, i, t}$ & $\begin{array}{l}1 \text { if at time } t, \text { crop } i \text { is selected to serve the potential biorefinery } \\
j\end{array}$ \\
\hline$Q_{i, j, p, t}$ & $\begin{array}{l}\text { Tons of product } p \text { bought in crop } i \text { at time } t \text { to serve potential } \\
\text { location } j\end{array}$ \\
\hline$C_{p, i, t}$ & Biorefinery $j$ consumption of product $p$ at time $t$ \\
\hline$S_{j, p, t}$ & $\begin{array}{l}\text { Stock corresponding to potential location } j \text { of product } p \text { at time } \\
t \text { in }\end{array}$ \\
\hline
\end{tabular}

Table 4. Description of parameters

\begin{tabular}{|c|l|c|c|}
\hline Parameter & \multicolumn{1}{|c|}{ Description } & Value & Unit \\
\hline$h_{p}$ & humidity of product $p$ & $10-58$ & $\%$ \\
\hline$\theta_{p, t}$ & 1 if product $p$ is available at $t$ & 0 or 1 & - \\
\hline$d_{i, j}$ & distance from crop $i$ to potential location $j$ & $0-200$ & $\mathrm{~km}$ \\
\hline$\varphi_{p}$ & season duration of product $p$ & $2-8$ & months \\
\hline$q_{i, p}$ & total production of $p$ in $i$ & $0-10,000$ & Tn \\
\hline$\alpha_{p, i}$ & exploitation factor of product $p$ in $i$ & $10-60$ & $\%$ \\
\hline$\delta$ & Depreciation rate during transportation & 0.5 & $\%$ \\
\hline$\gamma$ & Depreciation rate during storage & 1 & $\%$ \\
\hline
\end{tabular}

The problem formulation is as follows:

$$
\min \quad \text { Environmental Impact }=\sum_{j} \sum_{i} \sum_{t} Y_{j, i, t} d_{i, j}
$$

Subject to:

$$
\begin{array}{lr}
\sum_{j} X_{j}=1 & \\
\sum_{i} Q_{p, i, t, j}(1-\gamma)+S(1-\delta)=\frac{C_{p, j, t}}{1-h_{p}}+S_{p, t, j} ; & \forall p, \forall j, \forall t \\
\sum_{p} C_{p, j, t}=12500 X_{j} ; & \forall j, \forall t \\
Q_{p, i, t, j} \leqslant \text { AvaiBio }_{p, i, t} Y_{j, i, t} ; & \forall i, \forall p, \forall j, \forall t \\
Y_{j, i, t} \leqslant X_{j} ; & \forall j, \forall t, \forall i \\
Y_{j, i, t} \in\{0,1\} & \\
X_{j} \in\{0,1\} &
\end{array}
$$


The constraint (2) determines that a single biorefinery can be placed. Restriction (3) describes storage flows, taking into account product humidity and potential losses due to both transportation and storage. Constraint (4) establishes biomass that can be bought. Constraint (5) determines biorefinery capacity. Finally, AvaiBio ${ }_{p, i, t}$ in constraint (4) is the total biomass available of product $p \in P$ in of crop $i \in I$ at in month $t \in T$. Note that it depends on product seasonality and on the availability factor $\alpha_{p, i}$ to ensure that the biorefinery is not going to take a huge portion of the total production $\left(q_{p, i}\right)$ as recommended by Luo et al. (2010).

$$
\operatorname{AvaiBio}_{p, i, t}=q_{p, i} \alpha_{p, i} \frac{\theta_{p, t}}{\varphi_{p}}
$$

The remaining constraints ensure that, whether if a biorefinery is not built, no crop can be assigned to it (6) and force the variables $Y_{j, i, t}(7)$ and $X_{j}$ (8) to be binary variables.

\section{RESULTS}

The MILP model was coded in GAMS software using a commercial solver to solve it running on a personal computer (Intel ${ }^{\circledR}$ Core $^{\mathrm{TM}}$ i5-2430M CPU @2.40 GHz, and 4 GB RAM). Figure 1 also shows the chosen location chosen (red star). In order to get a better understanding of the results, Figure 2 shows the sensitivity analysis of the environmental impact versus a cost minimization objective once the facility is already up and running.

Note that (i) Input costs are made up of the cost of buying the biomass. The (ii) Transport costs are made up of the costs of transporting the biomass using the fix and distance-payload-based costs. This is the reason why transport costs are greater in the environmental minimization problem than in the costs minimization problem. Vehicles go to closer crops many times, increasing the fix cost of transportation. Finally, (iii) Stock costs are made up of the cost of storage the biomass.

Therefore, the traditional cost minimization problem was optimized using additional cost-related parameters (Tab. 5) and the following objective function, subject to the previous constraints.

$$
\begin{aligned}
\text { min Cost } & =\text { InputCost }+ \text { TransportCost }+ \text { StockCost } \\
\text { InputCost } & =\sum_{i} \sum_{p} \sum_{j} \sum_{t} Q_{i, j, p, t} p_{p} \\
\text { TransportCost } & =\sum_{i} \sum_{p} \sum_{j} \sum_{t}\left(F C+V C d_{i, j}\right) Q_{i, j, p, t} \\
\text { StockCost } & =\sum_{p} \sum_{j} \sum_{t} S_{j, p, t}
\end{aligned}
$$


Table 5. Description of cost-related parameters

\begin{tabular}{|c|l|c|c|}
\hline Parameter & \multicolumn{1}{|c|}{ Description } & Value & Unit \\
\hline$p_{p}$ & price of product $p$ & $45-105$ & $€$ \\
\hline$F C$ & transportation fix cost & 8.23 & $€ / \mathrm{Tn}$ \\
\hline$V C$ & transportation variable cost & 0.094 & $€ / \mathrm{Tn} / \mathrm{km}$ \\
\hline$s$ & stock cost & 0.945 & $€ / \mathrm{Tn} / \mathrm{month}$ \\
\hline
\end{tabular}

In the first step, the Green FLP is solved, giving us the best location among the tactical and operational policies (crop selection, purchase policies, and stock policies) as well as its total costs. That is Point A in Figure 2.

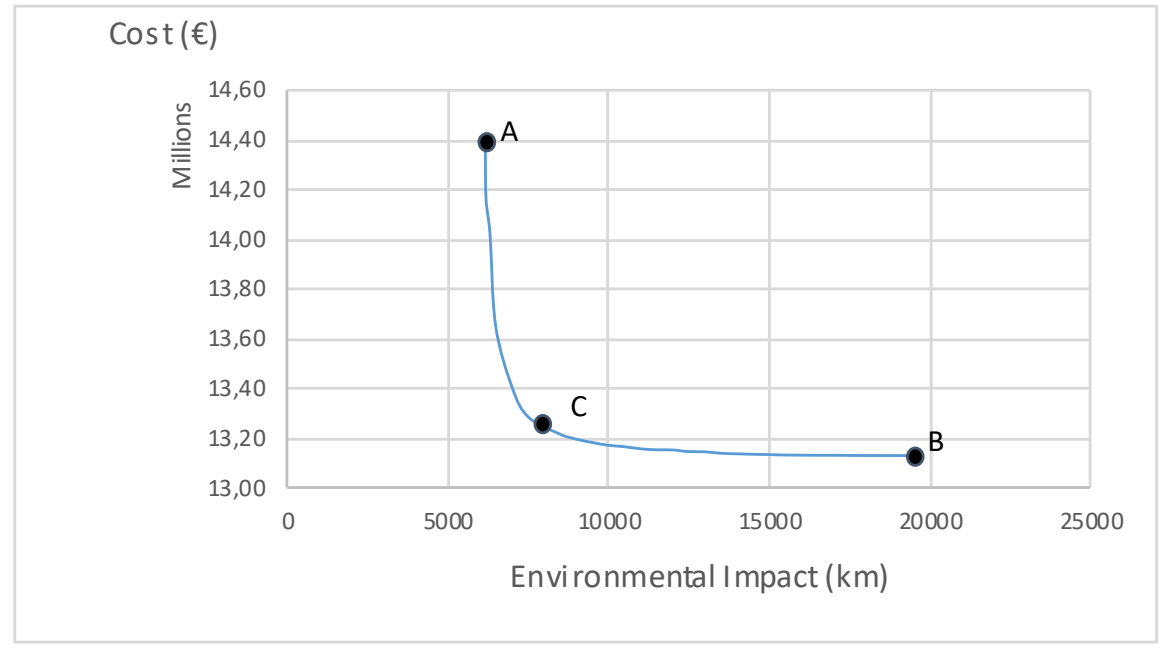

Fig. 2. Sensitivity Analysis Cost vs. Environmental Impact

In the second step, the location is fixed, and the sensitivity analysis is applied by relaxing the environmental impact; actually, Point B corresponds to the solution of the traditional cost minimization problem. This was made by including the environmental impact as a new constraint for the traditional cost minimization model:

$$
\text { Environmental Impact }=\sum_{j} \sum_{i} \sum_{t} Y_{j, i, t} d_{i, j} \leqslant \varepsilon
$$

where $\varepsilon$ initially takes the value of the environmental impact obtained from the cost minimization problem to be later gradually diminished. Finally, note that real biomass prices, transportation, and storage costs have been taken into account in the economic valuation. However, the reader should keep in mind that the Green FLP is solved once to determine the location. Later, a traditional cost optimization model can be run, but the location is already solved/fixed. Find in Table 6 the numerical results for three different designs in terms of input, transport, and storage management: the one 
minimizing distances (corresponding to Point A in Figure 2), the one minimizing costs (corresponding to Point B in Figure 2) and an arbitrarily chosen intermediate design (Point C).

Table 6. Summary of results

\begin{tabular}{|c|c|c|c|c|c|c|}
\cline { 4 - 7 } \multicolumn{2}{|c|}{} & \multirow{2}{*}{$\begin{array}{c}\text { Distance } \\
(\mathbf{k m})\end{array}$} & \multicolumn{4}{c|}{ Costs $(€)$} \\
\cline { 4 - 7 } \multicolumn{2}{|c|}{} & & Input & Transport & Stock & Total \\
\hline Min Envi Imp & Design A & 6,158 & $11,227,480$ & $2,371,526$ & 783,055 & $14,382,061$ \\
\hline \multicolumn{2}{|c|}{ Design C } & 8,351 & $10,235,358$ & $2,335,845$ & 690,859 & $13,262,062$ \\
\hline Min Costs & Design B & 19,866 & $10,121,590$ & $2,330,884$ & 681,209 & $13,133,683$ \\
\hline
\end{tabular}

As can be seen in Figure 2, the differences in terms of environmental impact and cost can be significant, being the decision maker able to choose among all of the efficient lines that correspond to different tactical and operational configurations: crop selection, purchase policies, and stock policies. Actually, the greener the supply chain is, the higher is its cost. Finally, note that there is a Point $\mathrm{C}$ at which it may not be worth continuing to green the supply chain beyond that point, because a higher environmental impact reduction would involve great increases in cost. By doing so, the minimum cost is not achieved (this would be Point B); nonetheless, a huge environmental impact is reached (57\% reduction) by slightly increasing costs (around $1 \%$ ).

\section{CONCLUSIONS AND MANAGERIAL INSIGHTS}

Facility location decisions are strategic, having influence in forthcoming tactical and operational results. The underestimation of the importance of facility location decisions would lead them to being vulnerable to several threats that may jeopardize their very survival. The Facility Location Problem faces this situation in such a way that potential locations are evaluated in order to choose a suitable place that may have to do with a coverage objective (such as locating a hospital) or classical cost minimization. However, a Green Facility Location Problem is introduced in this paper with the aim of choosing the location that minimizes the overall environmental impact that also takes into account tactical and operational decisions. A case study has been carried out in which a biorefinery should be located in a manner to care about both economic costs and environmental impacts. Biorefinery management would take advance of a sensitivity analysis in order to identify its key processes that allow them to empower their performance at both the economic and environmental levels. Management can adjust tactical and operational characteristics to choose the point they prefer in the sensitivity analysis (Fig. 2) once the Green FLP has selected the location. Finally, a deeper analysis covering additional factors affecting the environmental impact of facility location is expected in future research. Factors such as payload, road gradient, and driver behavior would also play determinant roles in defining environmentalfriendly location decisions. 


\section{ACKNOWLEDGEMENTS}

This work has been partially supported by the Spanish Ministry of Economy and Competitiveness (TRA2013-48180-C3-P and TRA2015-71883-REDT), and the Ibero-American Program for Science and Technology for Development (CYTED2014-515RT0489). Likewise, we want to acknowledge the support received by CAN Foundation in Navarre, Spain (Grant CAN2015-70473). This work has been also partially supported by the National Research Center (NCN), Poland (DEC-2013/11/B/ST8/04458), by AGH. Financial support from the Spanish Ministry of Education (FPU grant 14/00024) is gratefully acknowledged. Finally, the ICIL reviewers are also acknowledged for their helpful comments.

\section{REFERENCES}

Aytug, H., Saydam, C., 2002. Solving large-scale maximum expected covering location problems by genetic algorithms: A comparative study. European Journal of Operational Research, 141(3), pp. 480-494.

Bashiri, M., Rezanezhad, M., 2015. A reliable multi-objective p-hub covering location problem considering of hubs capabilities. International Journal of Engineering, Transactions B: Applications, 28(5), pp. 717-729.

Beliën, J., De Boeck, L., Colpaert, J., Devesse, S., Bossche, F., 2013. Optimizing the facility location design of organ transplant centers. Decision Support Systems, 54(4), pp. 15681579 .

Berman, O., Krass, D., Menezes, M., 2007. Facility reliability issues in network p-median problems: Strategic centralization and co-location effects. Operations Research, 55(2), pp. 332-350.

Bieniek, M., 2015. A note on the facility location problem with stochastic demands. Omega, 55, pp. 53-60.

Börjesson, M., Ahlgren, E., Lundmark, R., Athanassiadis, D., 2014. Biofuel futures in road transport - A modeling analysis for Sweden. Transportation Research Part D: Transport and Environment, 32, pp. 239-252.

Chatterjee, D., Mukherjee, B., 2013. Potential Hospital Location Selection using AHP: A Study in Rural India. International Journal of Computer Applications, 71(17), pp. 1-17.

Cherubini, F., Jungmeier, G., Wellisch, M., Willke, C., Skiadas, I., Ree, R., Jong, E., 2009. Toward a common classification approach for biorefinery systems. Biofuels, Bioproducts and Biorefining, 3(5), pp. 534-546.

Daskin, M., 2013. Network and Discrete Location: Models, Algorithms, and Applications. Second Edition, John Wiley \& Sons, New York.

Demir, E., Bektas, T., Laporte, G., 2014. A review of recent research on green road freight transportation. European Journal of Operational Research, 237, pp. 775-793.

Department of Agriculture of Navarre, 2016. Encuesta Agraria. URL: http://www.navarra.es/home_es/Temas/Ambito+rural/Vida+rural/Observatorio+ agrario/Agricola/Informacion+estadistica/produccion+agricola.htm (in Spanish, accessed on: 12 January 2017). 
European Environment Agency, 2015. EU fuel quality monitoring - 2014. Summary report http://www.eea.europa.eu/publications/eu-fuel-quality-monitoring-2014 (accessed on: 12 January 2017)

Gutjahr, W., Dzubur, N., 2016. Bi-objective bilevel optimization of distribution center locations considering user equilibria. Transportation Research Part E: Logistics and Transportation Review, 85, pp. 1-22.

Harris, I., Mumford, C.L., Naim, M.M., 2014. A hybrid multi-objective approach to capacitated facility location with flexible store allocation for green logistics modeling. Transportation Research Part E: Logistics and Transportation Review, 66, pp. 1-22.

Juan, A., Mendez, C., Faulin, J., de Armas, J., Grasman, S., 2016. Electric Vehicles in Logistics and Transportation: A Survey on Emerging Environmental, Strategic, and Operational Challenges. Energies, 9(2), pp. 1-21.

Koç, Ç., Bektaş, T., Jabali, O., Laporte, G., 2016. The impact of depot location, fleet composition and routing on emissions in city logistics. Transportation Research Part B: Methodological, 84, pp. 81-102.

Lee, J., Lee, Y., 2010. Tabu based heuristics for the generalized hierarchical covering location problem. Computers and Industrial Engineering, 58(4), pp. 638-645.

Lera-López, F., Faulin, J., Sánchez, M., Serrano-Hernandez, A., 2014. Evaluating factors of the willingness to pay to mitigate the environmental effects of freight transportation crossing the Pyrenees. Transportation Research Procedia, 3, pp. 423-432.

Liu, Z., Qiu, T., Chen, B., 2014. A study of the LCA based biofuel supply chain multi-objective optimization model with multi-conversion paths in China. Applied Energy, 126, pp. 221-234.

Luo, L., Voet, E., Huppes, G., 2010. Biorefining of lignocellulosic feedstock - Technical, economic and environmental considerations. Bioresource Technology, 101(13), pp. 5023-5032.

Martínez, J.C.V., Fransoo, J.C., 2017. Green Facility Location. In: Bouchery, Y., Corbett, C.J., Fransoo, J.C., Tan, T. (eds.), Sustainable Supply Chains: A Research-Based Textbook on Operations and Strategy, Springer International Publishing, Cham, pp. 219-234.

Marvin, W., Schmidt, L., Daoutidis, P., 2012. Biorefinery location and technology selection through supply chain optimization. Industrial and Engineering Chemistry Research, 52(9), pp. 3192-3208.

Melo, M.T., Nickel, S., Saldanha-Da-Gama, F., 2009. Facility location and supply chain management - A review. European Journal of Operational Research, 196(2), pp. 401-412.

Memişoğlu, G., Üster, H., 2015. Integrated Bioenergy Supply Chain Network Planning Problem. Transportation Science, 50, pp. 35-36.

Montoya, A., Vélez-Gallego, M., Villegas, J., 2016. Multi-product capacitated facility location problem with general production and building costs. NETNOMICS: Economic Research and Electronic Networking, 1, pp. 1-24.

Ortiz-Astorquiza, C., Contreras, I., Laporte, G., 2015. Multi-level facility location as the maximization of a submodular set function. European Journal of Operational Research, 247, pp. 1013-1016.

Papendiek, F., Tartiu, V., Morone, P., Venus, J., Hönig, A., 2016. Assessing the economic profitability of fodder legume production for Green Biorefineries: A cost-benefit analysis to evaluate farmers profitability. Journal of Cleaner Production, 112, pp. 3643-3656. 
Sakakibara, K., Tian, Y., Nishikawa, I., 2012. An Incremental Approach for Storage and Delivery Planning Problems. Decision Making in Manufacturing and Services, 6(1), pp. $5-23$.

Serrano-Hernandez, A., Faulin, J., Astiz, P., Sánchez, M., Belloso, J., 2015. Locating and Designing a Biorefinery Supply Chain under Uncertainty in Navarre: A Stochastic Facility Location Problem Case. Transportation Research Procedia, 10, pp. 704-713.

Shavandi, H., Mahlooji, H., 2006. A fuzzy queuing model with a genetic algorithm for congested systems. Applied Mathematics and Computation, 181(1), pp. 440-456.

You, F., Tao, L., Graziano, D., Snyder, S., 2012. Optimal design of sustainable cellulosic biofuel supply chains: Multiobjective optimization coupled with life cycle assessment and input-output analysis. American Institute of Chemical Engineers Journal, 58, pp. $1157-1180$.

Yu, E., Lixia, H., English, B., Larson, J., 2014. GIS-based optimization for advanced biofuels supply chains: A case study in Tennessee, Lecture Notes in Management Science, 6, pp. 217-227.

Zanjirani, R., Hekmatfar, M., 2009. Facility Location Concepts, Models, Algorithms and Case Studies, Physica Verlag.

Zhao, J., Verter, V., 2015. A bi-objective model for the used oil location-routing problem. Computers and Operations Research, 62, pp. 157-168. 